\title{
Educomunicação, paradigma indispensável à renovação curricular no ensino básico no Brasil ${ }^{1}$
}

Ismar de Oliveira Soares ${ }^{2}$

Professor Titular Sênior da Escola de Comunicação e Artes da Universidade de São Paulo (ECA-USP) e Presidente da Associação Brasileira de Pesquisadores e Profissionais da Educomunicação (ABPEducom). E-mail: ismarolive@yahoo.com

Resumo: Este artigo discute a indispensabilidade da prática educomunicativa na implementação de uma reforma curricular que leve em conta as demandas por uma educação cidadã que privilegie a formação para o exercício do direito universal à expressão e à comunicação. Toma como objeto de análise a versão definitiva da Base Nacional Comum Curricular (BNCC) do MEC, aprovada em dezembro de 2017, observando a natureza das premissas que abrem perspectivas para a inclusão da educação midiática como prática de interesse para o sistema educativo. $\mathrm{O}$ artigo lembra, finalmente, a expectativa criada pelo documento oficial quando prevê a atuação, no âmbito escolar, de curadorias e mediações especializadas para o tratamento de temas para os quais ainda não existam docentes especificamente formados. Entende-se que esse dispositivo abre caminho para a presença do especialista em Educomunicação nos quadros profissionais de atendimento à educação básica.

Palavras-chave: educomunicação; reforma curricular; educação cidadã; Base Nacional Comum Curricular.
Abstract: This article discusses the indispensability of the educommunicative practice for implementing a curriculum reform that considers the demands for a citizen education that focuses on a training for people to exercise their universal right to expression and communication. It aims to analyze the final version of the National Common Curriculum Base (BNCC - Base Nacional Comum Curricular) of the Brazilian Ministry of Education (MEC), passed in December 2017, observing the nature of the premises that open perspectives for the inclusion of media education as a practice of interest to the educational system. It also recalls the expectation created by the official document, since it predicted the performance, in the school context, of specialized curatorships and mediations to approach topics that still do not have specifically trained teachers. It is understood that this device opens the way for the presence of a specialist in Educommunication in the professional staff of elementary education.

Keywords: educommunication; curriculum reform; citizen education; Base Nacional Comum Curricular.
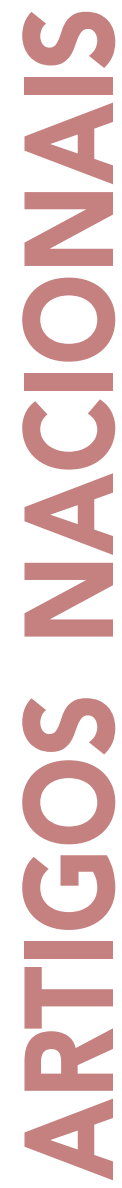

Recebido: $24 / 02 / 2018$

Aprovado: 27/03/2018

1. Artigo escrito a partir do paper "Inovação na gestão e nas práticas pedagógicas: a contribuição da educomunicação para a renovação da base curricular nacional", apresentado na sessão de encerramento do VII Congresso de Educação Básica promovido pela Secretaria de Educação do Município de Florianópolis na capital catarinense, no dia 6 de fevereiro de 2018.

2. O autor supervisionou projetos de educação midiática em vários estados do Brasil nas décadas de 1970 e 1980, especialmente o Projeto Leitura Crítica da Comunicação (LCC) da União Cristã Brasileira de Comunicação Social (UCBC), 
comunicação \& educação • Ano XXIII • número 1 • jan/jun 2018

implementado inicialmente junto ao Movimento Popular e, na sequência, em escolas privadas e públicas. Liderou, em 1996, a criação do Núcleo de Comunicação e Educação da Universidade de São Paulo (NCE-USP), a partir do qual coordenou a pesquisa que sistematizou o conceito de educomunicação (1997-1999). A partir do ano 2000, supervisionou uma série de programas de formação de professores/alunos, entre os quais - Educom.rádio (Prefeitura de São Paulo, 2001-2004) para 11 mil professores/alunos do ensino fundamental; o Educom.tv (2002), semipresencial, para 2.500 professores de 1.020 escolas da rede estadual de educação, em São Paulo; o Educomrádio. Centro-Oeste (2004-2005) para 2.000 professores e alunos dos estados do Mato Grosso, Goiás e Mato Grosso do Sul; e o Mídias na Educação, iniciativa do MEC que atendeu docentes matriculados em escolas do estado de São Paulo entre 2006 e 2012 formando 450 professores em nível de especialização e 6.500 em nível de aper-

feiçoamento. Articulou a criação da Licenciatura em Educomunicação da Escola de Comunicações e Artes da USP, da qual foi coordenador.

3. LOPES, Marina; OLIVEIRA, Vinícius de. As oportunidades e os riscos com a chegada da Base Nacional. Porvir, São Paulo, 22 dez. 2017. Inovações em Educação. Disponível em: <http://porvir.org/ a s-oportunidadese-os-riscos-com-a-chegada -da-base-nacional/>. Acesso em: 8 jan. 2018.

4. Diretora do Instituto Inspirare.

5. LOPES; OLIVEIRA, op. cit.

6. Daniel Cara foi um dos protagonistas da mobilização pela aprovação do Plano Nacional de Educação (PNE) na Câmara dos Deputados. Foi escoIhido a personalidade da Educação em 2012, em enquete coordenada na

\section{A PROPOSTA DA BNCC E AS REAÇÕES QUE PROVOCOU}

O Ministério da Educação definiu em dois anos - a partir de dezembro de 2017 - o período de preparação para a implantação, em cada município do país, da nova Base Nacional Comum Curricular (BNCC). A necessidade imperiosa de dar início a uma reforma de tão grande alcance, em tão pouco tempo, deixou certa sensação de insegurança, preocupando muitos pesquisadores da área, gestores de redes municipais de ensino. Na verdade, os dois anos de consultas e debates e as três propostas produzidas não foram suficientes para mobilizar quem mais interessa: os professores de diferentes níveis e áreas da docência no ensino básico.

Na realidade, foram basicamente de três ordens as reações da sociedade diante do novo dispositivo: apoio entusiasmado, de um lado, contestação radical, de outro, convivendo tais posições com uma pouco disfarçada indiferença, decorrente, entre outros motivos, da crise de confiança e da gravidade da situação político-econômica vivida pelo país nos anos finais da segunda década do século XXI, com efetivas perdas para a área da educação pública. Fixamo-nos nas duas primeiras.

\section{1 apoio: oportunidade para "alavancar inovações"}

O site do Porvir, organização do terceiro setor dedicada a pesquisas e assessorias em educação, apoiou com entusiasmo a inciativa, ainda que com ressalvas. No artigo "As oportunidades e os riscos com a chegada da Base Nacional”, assinado por Marina Lopes e Vinícius de Oliveira, a organização considerou que a BNCC trazia:

oportunidades para alavancar a inovação na educação brasileira, considerando a contemporaneidade do projeto, que foca no desenvolvimento integral, na multidimensionalidade e nas competências gerais, sintonizadas com as demandas da sociedade do século 21, criando referências para que redes, escolas e professores saibam o que é esperado de cada um deles ${ }^{3}$.

$\mathrm{O}$ artigo deu ênfase especialmente à interpretação de Anna Penido ${ }^{4}$, para quem o projeto teria a virtude de converter-se num "ponto de partida para promover a equidade, já que apresenta uma série de direitos de aprendizagem que precisam ser assegurados para todas crianças, adolescentes e jovens"

\subsection{Contestação: o que diriam Anísio Teixeira e Paulo Freire?}

Em posição de confronto à iniciativa do MEC, Daniel Cara ${ }^{6}$, coordenador-geral da Campanha Nacional pelo Direito à Educação, afirma que "a BNCC reduz o trabalho pedagógico dos professores a uma lista de conteúdos que devem ser cumpridos e (equivocadamente) transmitidos, tornando o processo de 
ensino-aprendizagem mimético, irrefletido e irrealizável"7. Para contextualizar historicamente sua avaliação, ele pergunta: "O que diriam sobre a base curricular os educadores Paulo Freire e Anísio Teixeira?”. E responde que, para Anísio Teixeira, a nova base curricular estaria contradizendo "uma experiência escolar significativa e democrática, orientada a educar ao invés de simplesmente instruir".

Já para Paulo Freire, a base curricular proposta pelo MEC "é a própria expressão da educação bancária, aquela que pressupõe que o aluno nada sabe e que o professor transmite o conhecimento, como se essa transmissão fosse possível em termos práticos”. Enfim, conclui:

Provavelmente, Paulo Freire anotaria que a novidade dessa BNCC é seu desserviço na promoção de um controle injusto do trabalho docente, desvencilhado da oferta de condições de trabalho aos educadores e da boa prática pedagógica, que é obrigatoriamente dialógica, emancipatória e construtiva ${ }^{10}$.

Em síntese, enquanto o apoio advém de setores preocupados com as inovações, a contestação apõe a questão do cotidiano da escola.

\subsection{A resposta antecipada do texto oficial}

Como que reagindo a futuras críticas como as que acabamos de transcrever, o documento do MEC antecipa-se, afirmando ser totalmente favorável a uma educação integral, porque integrada às "novas formas de existir" do educando brasileiro:

A BNCC propõe a superação da fragmentação radicalmente disciplinar do conhecimento, o estímulo à sua aplicação na vida real, a importância do contexto para dar sentido ao que se aprende e o protagonismo do estudante em sua aprendizagem e na construção de seu projeto de vida. Isso supõe considerar as diferentes infâncias e juventudes, as diversas culturas juvenis e seu potencial de criar novas formas de existir ${ }^{11}$.

As visões distintas fazem crer que o projeto é incontestavelmente polêmico, e que será implantado a partir de diferentes exegeses.

\section{QUEM TEM INTERESSE NESSA BASE NACIONAL COMUM CURRICULAR?}

Na introdução ao artigo em que abordamos a primeira versão da proposta do $\mathrm{MEC}^{12}$, o que identificamos em primeiro plano foi justamente a natureza polêmica do projeto governamental, cuja estrutura havia sido concebida, em 2015, por Janine Ribeiro ${ }^{13}$, então Ministro da Educação do governo Dilma Rousseff, em decorrência de um mandato do Plano Nacional de Educação (PNE) com vigência ente 2014 e 2024.

$\mathrm{O}$ anúncio da Base veio acompanhado de uma pesquisa coordenada por Antônio Augusto Gomes Batista, Rosario Lugli e Vanda Ribeiro, tendo como título "Centralização e padronização dos currículos: posições e tomadas de posição"14, internet pela Revista Nova Escola. Cf. mais informações no endereço disponível em: <https://novaescola.org.br/ conteudo/2814/conheca-daniel-cara-a-personalidade-da-educacao-em-2012>. Acesso em: 10 jan. 2018.

7. CARA, Daniel. \#BNCC: O que Paulo Freire e Anísio Teixeira diriam sobre a base curricular? UOL Educação, São Paulo, 20 dez. 2017. Blog do Daniel Cara. Disponível em: <https:// danielcara.blogosfera.uol. com.br/2017/12/20/bncc-oque-paulo-freire-e-anisio-teixeira-diriamsobre-a-base-curricular/ ?cmpid=copiaecola $>$. Acesso em: 10 jan. 2018.

8. Ibidem.

9. Ibidem.

10. Ibidem.

11. BRASIL. Ministério da Educação. Base Nacional Comum Curricular: educação é a base. 1. ver. Brasília, DF: MEC, 2016. p. 12-13.

12. SOARES, Ismar de Oliveira. A educomunicação possível: uma análise da proposta curricular do MEC para o Ensino Básico. Comunicacão \& Educação, São Paulo, v. 21, n. 1, p. 13-25, 2016b. Disponível em: $<$ http://www.revistas.usp. $\mathrm{br} / \mathrm{comueduc/article/}$ view/110451/112708> Acesso em: 17 abr. 2018.

13. Renato Janine Ribeiro é professor titular da cadeira de Ética e Filosofia Política da Faculdade de Filosofia, Letras e Ciências Humanas da Universidade de São Paulo (FFLCH-USP).

14. BATISTA, Augusto Gomes; LUGLI, Rosario; RIBEIRO, Vanda. Centralização e padronização dos currículos: posições e tomadas de posição. In: REUNIÃO NACIONAL DA ANPED, 37., 2015, Florianópolis. Anais... Florianópolis: UFSC, 2015. p. 1-23. Disponível em: <http://37reuniao. anped.org.br/wp-content/ u plo a ds/2015/02/ Sess\%C3\%A3o-Especial05.pdf>. Acesso em: $17 \mathrm{abr}$. 2018. 
cujos resultados foram apresentados na 37르 Reunião Nacional da ANPEd, no espaço da UFSC (4 a 8 de outubro de 2015), numa sessão especial sobre "Políticas educacionais e currículo: interfaces na educação infantil e ensino fundamental". Pois bem, a análise dos especialistas mostrava um cenário visivelmente dividido sobre a proposta, especialmente entre organismos da sociedade civil, gestores educacionais e teóricos da área.

Segundo a pesquisa, o argumento mais forte a favor de um currículo padronizado justificava-se pela garantia de que seria ofertado um mesmo ensino para todos os estudantes do país. Os dados revelaram que tanto os administradores da educação quanto os membros das organizações sociais ouvidos - dois grupos majoritariamente favoráveis à ideia - pareciam optar por uma espécie de solução de compromisso: a defesa de um núcleo duro, válido nacionalmente, seria aceitável mediante a confirmação de uma expectativa de respeito à cultura local e à diversidade trabalhadas a partir de "projetos inovadores".

Já os gestores de escolas particulares de elite ficaram divididos: metade mostrou desinteresse pelo assunto, enquanto os outros $50 \%$ posicionaram-se contrariamente a qualquer tipo de padronização curricular. Igualmente divididos estavam os sindicatos da área: os mais influentes repudiavam a padronização curricular, utilizando o argumento da preservação da autonomia de trabalho dos professores; os menos influentes, por seu turno, caminhavam em sentido oposto, admitindo as vantagens da padronização curricular.

Quanto aos docentes do ensino básico, deixaram evidente que a questão não lhes dizia respeito. Apenas aguardavam as decisões das autoridades.

Segundo os pesquisadores, o discurso majoritário em torno da definição de uma base nacional comum parecia abrigar uma grande heterogeneidade de pensamentos, evidenciando interesses camuflados. Um dos interesses identificado pela crítica dizia respeito à possibilidade de uma possível naturalização de certo monopólio na produção, comercialização e distribuição de materiais didáticos, com o carreamento para conglomerados do setor editorial (parte deles nas mãos do capital internacional) das gigantescas inversões governamentais destinadas a subsidiar uma produção comum e universal, tendo como mercado todas as escolas do país, especialmente as públicas.

Em nosso artigo lembrávamos que o mais grave nesse projeto orquestrado de produção em larga escala seria, a juízo dos críticos, o estrangulamento a que ficariam sujeitos, concomitantemente, a liberdade de ensino das escolas e de seus docentes e o direito de acesso dos estudantes a materiais de qualidade produzidos por fontes diversificadas e alternativas.

Em razão dos dados levantados pela pesquisa da ANPEd, concordamos, na ocasião, com os analistas que entendiam que "antes de se pensar num projeto curricular comum seria preciso definir o tipo de educação que se pretende oferecer às crianças e aos jovens do Brasil de hoje"15. E concluíamos nossas observações: "ao trazer para a abertura deste artigo o contexto pedagógico e político do debate em torno da reforma das práticas curriculares nacionais, temos a expressa intenção de deixar evidenciado tanto as promessas quanto os dilemas que a proposta governamental coloca para os especialistas em educomunicação" ${ }^{\prime 16}$. Este continua sendo o propósito da análise da terceira e última versão da BNCG, objeto do presente texto. 


\section{QUE SINAL NOVO INTERESSA IDENTIFICAR?}

Com certeza não é propósito deste artigo analisar a proposta governamental sob a perspectiva do conceito de "inovação pedagógica" entendida como ação esporádica, evidenciada e publicizada em razão do sucesso de experiências alternativas ao cotidiano do fazer educacional, e geralmente concebida e ativada por instituições externas ao espaço escolar. Igualmente, deixamos para outros autores a análise da hipótese de que a prática que se quer sacralizar levaria à adoção de um modelo industrial de aprendizagem, definido por metas estabelecidas por setores específicos da sociedade alheios à escola, dentre os quais, o econômico. Tampouco interessa ao artigo perguntar sobre a atualidade do projeto pedagógico segundo a perspectiva do marketing que preside a adoção das Tecnologias da Informação e Comunicação (TIC) no ensino, em decorrência dos efeitos benéficos da era digital.

O que, sim, este artigo prefere é focar na justeza da hipótese segundo a qual estariam sendo criados, pela nova política pública, tempos e espaços que se abrem a programas pedagógicos favorecedores de práxis essencialmente valorizadora da ação comunicativa dos alunos e dos professores no cotidiano da escola, enquanto sujeitos portadores do direito à fala. $\mathrm{O}$ sinal novo que buscamos atende pelo nome de educomunicação!

Foi sob essa perspectiva que examinamos mais especificamente duas partes substanciais do documento do MEC: a referente às Competências Gerais, de um lado, e a concernente aos tópicos integrantes da Área de Linguagens, de outro. Identificamos nesses excertos uma efetiva abertura para a interface comunicação/ educação. Resta saber, contudo, a partir de que referenciais teóricos e de que condições didáticas a educação midiática (implícita no documento) será efetivamente levada em conta pelos gestores dos novos programas curriculares a serem desenhados e implantados em cada escola do ensino básico no Brasil. Pleiteamos que seja em conformidade com o artigo 19 da Declaração Universal dos Direitos Humanos ${ }^{17}$.

\section{AS COMPETÊNCIAS GERAIS E A EDUCAÇÃO MIDIÁTICA: UM DIÁLOGO POSSÍVEL?}

Até o presente momento, a denominada educação midiática - prática voltada à análise do impacto dos meios de comunicação na sociedade e à promoção do uso pedagógico dos recursos das tecnologias da comunicação e informação no cotidiano do ensino - esteve presente no Brasil através de ações esporádicas e localizadas, vinculadas à boa vontade de lideranças, tanto no âmbito da educação não formal quanto no espaço da formalidade escolar, chegando a contar, em alguns casos, com o apoio da estrutura de secretarias de educação.

Exemplos do apoio de políticas públicas a ações coordenadas de educação midiática são visíveis em dois casos paradigmáticos: no Rio de Janeiro, com o projeto de mídia-educaçã $0^{18,19,20}$, implementado pela Secretaria de Educação do

17. Reza o Artigo 19 da Declaração Universal dos Direitos Humanos: "Todo ser humano tem direito à liberdade de opinião e expressão; esse direito inclui a liberdade de, sem interferência, ter opiniões e de procurar, receber e transmitir informações e ideias por quaisquer meios e independentemente de fronteiras". A Educomunicação entende que cabe à escola - imprescindível papel de formar os cidadãos para o cumprimento deste direito. Disponível em: <https:// www.unicef.org/brazil/pt/ resources_10133.htm>. Acesso em: 12 maio 2018.

18. De tradição europeia e nascido no âmbito das práticas de ensino, o conceito "mídia-educação" (media education) foi sistematizado pela Unesco a partir do Congresso de Grunwald, na Alemanhã (Cf. documento Grunwald declaration on Media Education, de 1982. Disponível em: <http:// www.unesco.org/education/pdf/MEDIA_E.PDF> Acesso em: 17 abr. 2018.

19. Segundo Bévorte Belloni, o termo mídia-educação designa expressamente a prática pedagógica destinada a "oferecer a todos os cidadãos, principalmente aos jovens, as competências para saber compreender a informação, ter o distanciamento necessário à análise crítica, utilizar e produzir informações e todo tipo de mensagens" (Mídia-educação: conceitos, história e perspectivas. Educação \& Sociedade, Campinas, v. 30 , n. 109 , p. 1.081-1.102, set./dez. 2009. p. 1.081. Disponível em: $<$ http://scielo.br/pdf/es/ v30n109/v30n109a08.pdf/>. Acesso em: 17 abr. 2018.

20. Cf. sobre o tema da mídia-educação no Rio de Janeiro matéria feita pelo Canal Futura. Disponível em: <https://www.youtube. $\mathrm{com} / \mathrm{watch}$ ? $v=U 8 Z \mathrm{sK}$ vRFqxg>. Acesso em: 17 abr. 2018 
21. O conceito "educomunicação" aplica-se fundamentalmente às relações de comunicação em espaços educativos, buscando a implementação de uma gestão democrática dos recursos da informação com a participação de professores, estudantes e membros da comunidade educativa. Para tanto, faz-se útil e necessário o domínio de metodologias de análise em comunicação, em projetos voltados para a educação em direitos humanos, além do exercício da prática comunicativa a partir do protagonismo dos sujeitos sociais. Otermo tem sido adotado como política pública, em diferentes níveis de governo, nasáreas da educação e do meio ambiente, a partir de uma pesquisa desenvolvida pelo Núcleo de Comunicação eEducação da USP, entre 1997 e 1999 (SOARES, Ismar de Oliveira.

Comunicação/educação: a emergência de um novo campo e o perfil de seus profissionais. Contato, Revista Brasileira de Comunicação, Arte e Educação, Brasília, DF, ano 1, n. 2, p. 19-74, 1999). Sobre o conceito, sugerimos a leitura de dois artigos incluídos nas referências bibliográficas: o primeiro, com o título "Educomunicação: as múltiplas tradições de um campo emergente de intervenção social na Europa, Estados Unidos e América Latina" (SOARES,

2013) e o segundo, intitulado "Da comunicação popular à educomunicação: reflexões no campo da "educação como cultura" (MARQUES; TALARICO, 2016).

22. A razão básica do referido estranhamento residiuna origem dos dois conceitos. A educação midiática teve sua origem na Europa, a partir da visão que a educação formal - sob a liderança da Unesco - acabou construindo a respeito da mídia, criando referenciais teórico-metodológicos que auxiliassem os sistemas de ensino a enfrentar o impacto das mensagens sobre seus estudantes. Já a educomunicação emerge da interface comunicação/educação, em território latino-americano a partir. município com apoio da empresa MultiRio; e em São Paulo, com o projeto de educomunicação ${ }^{21}$ desenvolvido, igualmente, pela Secretaria de Educação da cidade, contando em sua formulação e implantação com a colaboração da USP.

Nos dois casos, as respectivas secretarias de educação necessitaram contar com a atuação de organismos externos (a empresa MultiRio e o Núcleo de Comunicação e Educação da USP, respectivamente) para operacionalizar suas propostas. Como resultado, as duas experiências eliminaram definitivamente a rigidez e as resistências de suas estruturas de ensino, tendo como efeito a introdução do novo, representado pela presença do universo midiático no espaço escolar.

Dadas suas respectivas origens, os dois conceitos (mídia-educação e educomunicação) se estranharam e viveram momentos de confronto nas últimas duas décadas, em toda a América Latina ${ }^{22}$. No entanto, o avanço das pesquisas e a troca de experiências permitiram um efetivo diálogo entre seus promotores. Exemplos dessa aproximação teórico-metodológica são, em nível continental, os projetos Las Otras Voces ${ }^{23}$ (Argentina) e Educom.rádio (Brasil) ${ }^{24}$, bem como, em nível nacional, o projeto Educom.geraçãocidadã ${ }^{25}$. Em termos acadêmicos, verifica-se igualmente, nos últimos anos, uma aproximação progressiva dos promotores dos dois conceitos ${ }^{26}$.

Para muitos, pode ter sido uma surpresa constatar que tema tão circunscrito na tradição pedagógica brasileira tenha obtido brechas significativas em cada uma das três sucessivas versões da BNCC, produzidas ao longo das duas últimas administrações federais. Quem acompanha, no Banco de Teses da Capes, a produção acadêmica de dissertações e teses a partir do ano $2000^{27}$ saberá entender a razão da circulação de informações e dados sobre a urgência de implementar políticas de educação midiática nos projetos curriculares nacionais. Não há dúvida de que os técnicos e assessores que trabalharam na redação dos projetos tiveram acesso, ainda que não sistemático, a esse saber recém-difundido.

No caso da versão definitiva da BNCC, a aproximação do tema da educação midiática ganha destaque, logo no início do documento, no subtítulo "Competências gerais da Base Nacional Comum Curricular" (páginas 7 e 8 ), em que, das dez referências, seis (as de número 3, 4, 5, 7, 9 e 10) mantêm algum vínculo teórico ou metodológico com o objeto de nossa reflexão: a "educação midiática e informacional".

No caso, são contemplados elementos que se relacionam à expressão cultural, ao uso das diferentes linguagens, à criação e à utilização de tecnologias digitais de informação e comunicação, sempre com a expressa recomendação de que isso se faça de forma crítica, significativa, reflexiva e ética. Finalmente, é indicado o emprego de práticas de gestão educomunicativa, para lembrar que as recomendações não se limitam ao universo da mídia-educação, mas se estendem ao domínio dos processos de gestão da prática comunicativa proposta pela educomunicação. 
Vejamos:

3. Valorizar e fruir as diversas manifestações artísticas e culturais, das locais às mundiais, e também participar de práticas diversificadas da produção artístico-cultural.

4. Utilizar diferentes linguagens - verbal (oral ou visual-motora, como Libras, e escrita), corporal, visual, sonora e digital -, bem como conhecimentos das linguagens artística, matemática e científica, para se expressar e partilhar informações, experiências, ideias e sentimentos em diferentes contextos e produzir sentidos que levem ao entendimento mútuo.

5. Compreender, utilizar e criar tecnologias digitais de informação e comunicação de forma crítica, significativa, reflexiva e ética nas diversas práticas sociais (incluindo as escolares) para se comunicar, acessar e disseminar informações, produzir conhecimentos, resolver problemas e exercer protagonismo e autoria na vida pessoal e coletiva ${ }^{28}$.

As competências identificadas pelos números sete, nove e dez do documento trazem temas especialmente caros à gestão educomunicativa:

7. Argumentar com base em fatos, dados e informações confiáveis, para formular, negociar e defender ideias, pontos de vista e decisões comuns que respeitem e promovam os direitos humanos, a consciência socioambiental e o consumo responsável em âmbito local, regional e global, com posicionamento ético em relação ao cuidado de si mesmo, dos outros e do planeta.

\section{$[\ldots]$}

9. Exercitar a empatia, o diálogo, a resolução de conflitos e a cooperação, fazendo-se respeitar e promovendo o respeito ao outro e aos direitos humanos, com acolhimento $e$ valorização da diversidade de individuos e de grupos sociais, seus saberes, identidades, culturas e potencialidades, sem preconceitos de qualquer natureza.

10. Agir pessoal e coletivamente com autonomia, responsabilidade, flexibilidade, resiliência e determinação, tomando decisões com base em princípios éticos, democráticos, inclusivos, sustentáveis e solidários ${ }^{29}$.

Com orientações como essas, expressas com suficiente clareza, de forma a não permitir enganos no desenho e implementação das futuras versões curriculares, estaria comprovado que efetivamente se instalou no país um diálogo entre as Competências Gerais da BNCC e as metas da educação midiática? Não existem certezas, sobretudo quando se leva em conta que as expressões usadas, caso não sejam parte da cultura que dá suporte ao plano curricular, soarão como frases soltas de mero discurso protocolar.

Caberá, naturalmente, aos mídia-educadores e aos educomunicadores discutir, na prática de cada caso, as especificidades do tratamento previsto para o processo pedagógico: se sob uma perspectiva iluminista-bancária ou se no contexto de um procedimento construtivista-dialógico ${ }^{30}$.

Aprofundamos, na sequência, as referências ao tema de nosso interesse, avançando na leitura do texto da Base. do reconhecimento pelas organizações sociais do direito universal à expressão e à comunicação. Aparece inicialmente como uma prática que entrelaça a educação popular e a comunicação alternativa. No caso, a mídia-educação tem como conceito chave a mídia, enquanto a educomunicação centra sua atenção nos processos comunicativos. Tais especificações não têm impedido uma mútua colaboração entre os promotores dos dois conceitos.

23. Cf. entrevista com a coordenadora do projeto Las Otras Voces, em Buenos Aires, no endereço disponível a seguir: <https:// youtube.com/wat ch?v=wNgJyakFu1l>. Acesso em: 17 abr. 2018.

24. As similitudes entre o projeto mídia-educativo Las Otras Voces, que implementou a prática de leitura da mídia e de produção radiofônica comjovens em 400 escolas da Argentina, de um lado, e o projeto Educom.rádio, que levou a educomunicação a 455 escolas da rede municipal de educação de São Paulo, de outro, foram objetos de um estudo comparado, em nível de mestrado, de autoria deAna Carolina AltieriSoares (Educomunicação e cidadania na América Latina. Ainterface comunicação/educação a partir das práticas sociais no continente: estudo de caso de políticas públicas na Argentina e no Brasil. 2012. 214f. Dissertação (Mestrado em Integração da América Latina) - Integração da América Latina, Universidade de São Paulo, São Paulo, 2012).

25. O projeto Educom. geração cidadã une duas escolas em São Paulo uma da rede pública (CEUEMEFCasa Blanca) e outra da rede privada (Colégio Dante Alighieri) - sob a articulação da Associação Brasileira de Pesquisadores e Profissionais em Educomunicação (ABPEducom), em atividades de análise de mídia e de prática educomunicativa. Cf. mais sobre o projeto no vídeo disponível em: $<$ https://www.youtube.com/ watch? $=\mid v T S q t T 1 x K k>$. Acesso em: 17 abr. 2018. 
comunicação \& educação • Ano XXIII • número 1 • jan/jun 2018

26. A título de exemplo, enquanto o MEC trabalhava na elaboração do texto final da BNCC, promotores e pesquisadores das áreas de mídia-educação e educomunicação reuniam-se no espaço da Escola de Comunicações e Artes da USP, em novembro de

2016, para participar do $\checkmark$ Global Media and Information Literacy Week (ou simplesmente Global MIL Week), uma iniciativa da Unesco, com o objetivo de ampliar o debate sobre a educação midiática e informacional em todos os seus âmbitos e potencialidades. No mesmo período e local, promovia-se o VII Encontro Brasileiro de Educomunicação, que trazia ao espaço compartilha-

do com o evento internacional um total de 400 especialistas vinculados aos dois paradigmas de ações de educação midiática. 0 fato registrou o fortalecimento de um movimento de aproximação entre os especialistas das duas áreas, a serviço de propósitos comuns. A documentação do VII Educom (com 120 papers, em 940 páginas) encontra-se registrada em SOARES VIANA; XAVIER (2017).

27. Levantamentos realizados no Banco de Teses da CAPES, em 28 de janeiro de 2018, apontaram para um total de 257 pesquisas (mestrados e doutorados) sobre práticas educomunicativas no Brasil, produzidas nos últimos 20 anos e defendidas em 81 centros de pós-graduação. Por outro lado, foram identificados 144 títulos de teses sobre mídia-educação, defendidas em 30 centros nacionais de pós- graduação em Educação.

28. Brasil. Base Nacional Comum Curricular. Brasília, DF: Ministério da Educação, 2017. p. 7.

Disponível em: http:// portal.mec.gov.br/index. php?option=com_docman v\&view=download\&alias $=$ 79601-anexo-texto-bncc-reexportado-pdf-2\&category slug=dezembro2017- pdf\&Itemid=30192 .

Acesso em: 12 maio 2018.

\section{A EDUCAÇÃO MIDIÁTICA ENTRE AS METAS PARA A EDUCAÇÃO INFANTIL}

Ao tratar da educação infantil, a BNCC explicita, a partir da página 34, o que espera dos pequenos, em sintonia com o que nós entendemos como práticas expressamente "educomunicativas". Destacamos duas das competências desejadas, quais sejam:

- Participar ativamente, com adultos e outras crianças, tanto do planejamento da gestão da escola e das atividades propostas pelo educador quanto da realização das atividades da vida cotidiana, desenvolvendo diferentes linguagens e elaborando conhecimentos, decidindo e se posicionando.

- Expressar, como sujeito dialógico, criativo e sensível, suas necessidades, emoções, sentimentos, dúvidas, hipóteses, descobertas, opiniões, questionamentos, por meio de diferentes linguagens ${ }^{31}$.

A quem duvide de metas tão ambiciosas, reportamos ao programa Imprensa Mirim, da rede municipal da Prefeitura de São Paulo, apresentado durante o V Global MIL Week da Unesco, em novembro de $2016^{32}$.

\section{A EDUCAÇÃO MIDIÁTICA ENTRE AS METAS PARA O ENSINO FUNDAMENTAL}

O documento do MEC lembra, entre as páginas 55 e 58, a importância de fortalecer a autonomia das crianças e adolescentes, de 6 a 14 anos, oferecendo-lhes condições e ferramentas para acessar e interagir criticamente com diferentes conhecimentos e fontes de informação.

\subsection{0 alerta inicial!}

Inicialmente, o texto se volta aos cuidados que os estudantes devem tomar em relação ao mundo das TIC, sugerindo aos educadores que introduzam o tema da mídia na plataforma curricular:

Os jovens têm se engajado cada vez mais como protagonistas da cultura digital, envolvendo-se diretamente em novas formas de interação multimidiática e multimodal e de atuação social em rede, que se realizam de modo cada vez mais ágil. Por sua vez, essa cultura também apresenta forte apelo emocional e induz ao imediatismo de respostas e à efemeridade das informações, privilegiando análises superficiais e o uso de imagens e formas de expressão mais sintéticas, diferentes dos modos de dizer e argumentar característicos da vida escolar ${ }^{33}$. 


\subsection{Proposições}

Num segundo momento, o texto do MEC retoma propostas já consagradas na literatura dedicada à educação midiática, contemplando duas competências: $\left(1^{\mathfrak{a}}\right)$ ser o jovem capaz de realizar a análise crítica da mídia e $\left(2^{\underline{a}}\right)$ ser o estudante capaz de dominar os elementos indispensáveis a uma produção midiática qualificada como democrática e participativa:

[1 $\left.1^{\mathfrak{a}}\right]$ Todo esse quadro impõe à escola desafios ao cumprimento do seu papel em relação à formação das novas gerações. É importante que a instituição escolar preserve seu compromisso de estimular a reflexão e a análise aprofundada e contribua para o desenvolvimento, no estudante, de uma atitude crítica em relação ao conteúdo e à multiplicidade de ofertas midiáticas e digitais. [2를 [...] também é imprescindível que a escola compreenda e incorpore mais as novas linguagens e seus modos de funcionamento, desvendando possibilidades de comunicação (e também de manipulação), e que eduque para usos mais democráticos das tecnologias e para uma participação mais consciente na cultura digital ${ }^{34}$.

O documento aponta, na sequência, o sentido ético do agir educomunicativo: "novos modos de aprendizagem" e "diálogo na convivência cotidiana":

Ao aproveitar o potencial de comunicação do universo digital, a escola pode instituir novos modos de promover a aprendizagem, a interação e o compartilhamento de significados entre professores e estudantes.

Além disso, e tendo por base o compromisso da escola de propiciar uma formação integral, balizada pelos direitos humanos e princípios democráticos, é preciso considerar a necessidade de desnaturalizar qualquer forma de violência nas sociedades contemporâneas, incluindo a violência simbólica de grupos sociais que impõem normas, valores e conhecimentos tidos como universais e que não estabelecem diálogo entre as diferentes culturas presentes na comunidade e na escola.

Em todas as etapas de escolarização, mas de modo especial entre os estudantes dessa fase do Ensino Fundamental, esses fatores frequentemente dificultam a convivência cotidiana e a aprendizagem, conduzindo ao desinteresse e à alienação e, não raro, à agressividade e ao fracasso escolar ${ }^{35}$.

As proposições 1 e 2 e seu complemento traduzem o que o paradigma educomunicativo tem como propósito específico no cotidiano escolar. O desafio é transformar tais princípios em metas exequíveis, coerentemente assumidas por todos os agentes do processo educativo.
29. Ibidem, p. 8.

30. A expressão "processo pedagógico" aqui indicada refere-se ao conjunto de procedimentos que permitirão aos alunos se apoderarem dos conceitos e práticas anunciadas como metas do projeto curricular. Resta saber se a via será de mão única, nos moldes da tradicional "educação bancária", ou se o projeto abrirá espaço para outras didáticas que possibilitem a produção de conhecimento porparte dos alunos numa perspectiva problematizadora, dialógica e colaborativa. Lembramos que para a segunda perspectiva, não basta "formar" o professor para que este "retransmita" os conteúdos aos alunos. No caso, toda a comunidade educativa deve participar-de forma colaborativa e em igualdade de condições-do processo formativo. Essa foi a razão do êxito do projeto Educom.rádio, que articulou a prática educomunicativa de 11 mil indivíduos, entre professores, estudantes e membros das comunidades educativas de 455 escolas da rede municipal de educação de São Paulo, entre 2001 e 2004, gerando uma cultura que persiste na rede até o presente momento. Sugerimos dois documentários no YouTube. O primeiro, de 2002, aborda a implantação do processo formativo (disponível em: <https://www. youtube.com/watch?v= FDEVvZY164U>. Acesso em: 18 abr. 2018), e o segundo, de 2017, a prática de um dos 700 projetos vigentes na atualidade na mesma rede (disponível em: $<$ https://www.youtube.com/ watch? $v=f b P 8 M J L A t 1 M>$. Acesso em: 18 abr. 2018).

31. Brasil, op. cit., 2017, p. 34

32. Sugerimos a visita a uma sequência de textos sobre a educomunicação na primeira infância e no ensino fundamental, disponibilizada no e-book Educomunicação e suas áreas de intervenção (op. cit.). Sugerimos igualmente a visita ao site da 
ABPEducom para contato com a matéria: "Educomunicação na educação infantil: TV Câmera entrevista coordenadores da Rádio Cartola". Cf. no endereço disponível em: $<$ www.abpeducom.org. br/educomunicacao-naeducacao-infantil-t$v$-camera-entrevista- coordenadores-da-radio-cartola/>. Acesso em: $18 \mathrm{abr} .2018$.

33. Brasil, op. cit., 2017, p. 57.

34. Ibidem.

35. Ibidem.

36. Ibidem, p. 57-58.

37. Ibidem, p. 58.

38. Em 2010, a Unesco disponibilizou um manual abrangente (WILSON, 2013).

39. Na BNCC, a Área de Linguagens é composta pelos seguintes componentes curriculares: língua portuguesa, arte, educação física e, no ensino fundamental - anos finais, língua inglesa. comunicação \& educação • Ano XXIII • número 1 • jan/jun 2018

\section{A ESTRUTURA DO DISCURSO SOBRE A EDUCAÇÃO MIDIÁTICA}

Impressiona constar que a BNCC tenha incorporado em suas proposituras primordiais não apenas os conteúdos, mas a própria estrutura do discurso proferido pelos mídia-educadores e educomunicadores há pelo menos quatro décadas. Por outro lado, o documento reconhece que a execução dessas premissas necessitará, por seu caráter transdisciplinar, de outros saberes que não apenas aqueles tradicionalmente exigidos dos professores das disciplinas do ensino fundamental.

Assim, de acordo com o texto da BNCC, o currículo deverá, de forma igual, buscar a diversidade de formação e levar em conta os conhecimentos e valores que os estudantes trazem consigo para a sala de aula, sendo indispensável para tanto:

a) prever e estimular a diversidade de formação e de vivências:

Atenta a culturas distintas, não uniformes nem contínuas dos estudantes dessa etapa, é necessário que a escola dialogue com a diversidade de formação e vivências para enfrentar com sucesso os desafios de seus propósitos educativos ${ }^{36}$.

b) incluir na roda os saberes dos próprios estudantes, adquiridos em sua relação com a cultura midiática:

A compreensão dos estudantes como sujeitos com histórias e saberes construídos nas interações com outras pessoas, tanto do entorno social mais próximo quanto do universo da cultura midiática e digital, fortalece o potencial da escola como espaço formador e orientador para a cidadania consciente, crítica e participativa.

Nessa direção, no Ensino Fundamental - Anos Finais, a escola pode contribuir para o delineamento do projeto de vida dos estudantes, ao estabelecer uma articulação não somente com os anseios desses jovens em relação ao seu futuro, como também com a continuidade dos estudos no Ensino Médio. Esse processo de reflexão sobre o que cada jovem quer ser no futuro, e de planejamento de ações para construir esse futuro, pode representar mais uma possibilidade de desenvolvimento pessoal e socia ${ }^{77}$.

Os argumentos trazidos a este artigo, até a presente página, atestam a convergência de sentidos e de propósitos entre, por um lado, o ideário de um currículo que se pretende atualizado com o mundo nesta virada de milênio e, por outro, as proposições articuladas em torno de uma educação midiática legitimada por instituições como a Unesco - organismo da ONU voltado às áreas de educação e cultura ${ }^{38}$. É pouco, contudo, circunscrever-nos aos tópicos iniciais da proposta da BNCC. Avancemos para as propostas específicas da Área de Linguagens.

\section{A COMUNICAÇÃO COMO OBJETO DE APRENDIZAGEM NA ÁREA DE LINGUAGENS ${ }^{39}$}

Faz-se oportuno e necessário efetivamente avançar para anotar o que o projeto do MEC propõe, a partir da página 59 de seu texto, que a área de 
Linguagens seja considerada, essencialmente, como um espaço dedicado às aprendizagens sobre a conformação dos sujeitos sociais, com o reconhecimento da importância das diferentes linguagens da comunicação - da corporal à digital - como fica explicitado no parágrafo a seguir:

As atividades humanas se realizam nas práticas sociais, mediadas por diferentes linguagens: verbal, corporal, visual, sonora e, contemporaneamente, digital. Por meio dessas práticas, as pessoas interagem consigo mesmas e com os outros, constituindo-se como sujeitos sociais. Nessas interações, estão imbricados conhecimentos, atitudes e valores culturais, morais e éticos ${ }^{40}$.

É nessa perspectiva, pois, que cabe à escola

possibilitar aos estudantes participar de práticas de linguagem diversificadas, de forma a que se ampliem suas capacidades expressivas em manifestações artísticas, corporais e linguísticas, como também seus conhecimentos sobre essas linguagens, em continuidade às experiências vividas na Educação Infantil ${ }^{41}$.

Considerando esses pressupostos, e em articulação com as Competências Gerais da BNCC, essa área específica deve garantir aos alunos o desenvolvimento de habilidades para que se expressem e partilhem informações, experiências, ideias e sentimentos em diferentes contextos e produzam sentidos que levem ao diálogo, à resolução de conflitos e à cooperação.

Nesse sentido, merecem destaque, entre as competências esperadas para a área de Linguagens, os tópicos 5 e 6 , referentes, respectivamente, à íntima relação entre desenvolvimento do senso estético e respeito à diversidade, por um lado, e o uso das tecnologias e o sentido autoral de seu emprego, por outro:

Competência 5 - Desenvolver o senso estético para reconhecer, fruir e respeitar as diversas manifestações artísticas e culturais, das locais às mundiais, inclusive aquelas pertencentes ao patrimônio cultural da humanidade, bem como participar de práticas diversificadas, individuais e coletivas, da produção artístico-cultural, com respeito à diversidade de saberes, identidades e culturas.

Competência 6 - Compreender e utilizar tecnologias digitais de informação e comunicação de forma crítica, significativa, reflexiva e ética nas diversas práticas sociais (incluindo as escolares), para se comunicar por meio das diferentes linguagens e mídias, produzir conhecimentos, resolver problemas e desenvolver projetos autorais e coletivos ${ }^{42}$.

Em outras palavras, o documento assegura aos estudantes o direito de:

a) participar de práticas de linguagem diversificadas, incluindo as linguagens visual, sonora e digital;

b) ampliar suas capacidades expressivas em manifestações artísticas, corporais e linguísticas;

c) ampliar seus conhecimentos sobre essas mesmas linguagens.

Novamente, voltamos à advertência registrada ao final do item 4 (sob qual perspectiva serão produzidos os currículos: a "iluminista-bancária" ou a "construtivista-dialógica"?). Repetimos: resta, pois, saber em que condições, de
40. Brasil, op. cit., 2017, p. 59.-MEC. A Base Nacional Comum Curricular, Introdução: Competências Gerais da BNCC, Brasília, 2017. Idem, p. 59. Acesso em: 12 de maio de 2018.

41. Ibidem.

42. Ibidem, p. 61. Acesso em: 12 de maio de 2018. 
que maneira e em que espaços curriculares os aprendizados sobre as diferentes linguagens, incluindo as midiáticas e digitais, serão assegurados no momento de explicitar tais normas em projetos curriculares específicos.

No próximo tópico será tratado o tema da responsabilidade pelo trabalho com as diferentes linguagens no ensino fundamental. Haveria lugar para um novo profissional no espaço escolar?

\section{ABERTURA PARA A PRESENÇA NA ESCOLA DE ESPECIALISTAS EM EDUCAÇÃO MIDIÁTICA}

Nas páginas 65 a 67 do documento, a BNCC refere-se ao âmbito próprio da disciplina de língua portuguesa, destacando sua missão de ampliar o letramento dos estudantes do ensino básico, envolvendo no conteúdo disciplinar os gêneros e textos multimidiáticos como forma de "produzir, configurar, disponibilizar, replicar e interagir" ${ }^{43}$.

Para tanto, são incluídas referências explícitas às novas ferramentas de edição de texto, áudio, foto e vídeo que tornam acessíveis a qualquer um a produção e a disponibilização de textos multissemióticos nas redes sociais e outros ambientes da web: "[n]ão só é possível acessar conteúdos variados em diferentes mídias, como também produzir e publicar fotos, vídeos diversos, podcasts, infográficos, enciclopédias colaborativas, revistas e livros digitais etc." ${ }^{\prime 4}$.

\subsection{A necessidade da previsão de formação expressa para os alunos}

Lembra, contudo, a BNCC que estar o aluno familiarizado com os novos recursos não significa, necessariamente, que ele já seja capaz de levar em conta “as dimensões ética, estética e política desse uso" ${ }^{\text {* }}$. No caso, os alunos necessitam obrigatoriamente de uma formação específica para lidar, de forma experimental e autoral, com o universo da mídia, no contexto de uma cultura em permanente mutação.

Tal formação, por sua vez, por ser específica, precisará contar com a colaboração de mediadores educacionais que ajudem os alunos a avançar em suas produções de conhecimento a respeito de tema tão complexo.

43. Ibidem, p. 62.

44. Ibidem, p. 64 45. Ibidem, p. 64.

\subsection{Curadores e curadorias}

É melhor que tais mediadores sejam profissionais já integrados aos quadros da rede de ensino (docentes com formação suplementar em mídia-educação e/ ou educomunicação). O texto da BNCC define, contudo, que, na falta de especialistas da casa, as escolas contem com "curadores" para temas inovadores que não pertençam ao cotidiano do ensino tradicional. Nessa linha, ficam os sistemas 
escolares autorizados a contratar "mediadores" em condições de dar assistência aos alunos em suas aprendizagens. Estamos, na verdade, traduzindo o texto do MEC quando este se refere a "curadorias" e "curadores", trazendo para a gestão curricular um termo próprio da área da cultura: "[p]assamos, então, a depender de curadores ou de uma curadoria própria, que supõe o desenvolvimento de diferentes habilidades" ${ }^{\prime 4}$.

Na realidade, o texto legitima a contratação pelo sistema público de educação de organizações e empresas que prestam serviços para a área educacional. O que acrescentamos é que tal disposição, quando conveniente, facilite de forma igual o trabalho nas escolas públicas de especialistas em mídia-educação e educomunicação.

\section{UM ROTEIRO PARA O PLANEJAMENTO DA EDUCAÇÃO MIDIÁTICA}

O especialista em educação midiática proposto pela BNCC (seja o próprio professor do ensino fundamental, ou coordenadores de projetos especiais em educomunicação ou mídia-educação) deverá - como descrito ao longo das páginas 65 a 67 do documento - cumprir duas tarefas, especificadas no tratamento que o documento pretende que seja dado aos conteúdos indicados:

1. Promover as competências de "leitura" dos alunos, através de propostas pedagógicas que facilitem a análise do que circula na mídia e especialmente nas redes sociais. A título de exemplo, o texto oficial do MEC sugere reflexões sobre os limites entre "liberdade de expressão" e "ataque a direitos":

É preciso saber reconhecer os discursos de ódio, refletir sobre os limites entre liberdade de expressão e ataque a direitos, aprender a debater ideias, considerando posições e argumentos contrários. Não se trata de deixar de privilegiar o escrito/ impresso nem de deixar de considerar gêneros e práticas consagrados pela escola, tais como notícia, reportagem, entrevista, artigo de opinião, charge, tirinha, crônica, conto, verbete de enciclopédia, artigo de divulgação científica etc., próprios do letramento da letra e do impresso, mas de contemplar também os novos letramentos, essencialmente digitais ${ }^{47}$.

\section{Incentivar as competências de "produção" em diferentes linguagens:}

Como resultado de um trabalho de pesquisa sobre produções culturais, é possível, por exemplo, supor a produção de um ensaio e de um vídeo-minuto. No primeiro caso, um maior aprofundamento teórico-conceitual sobre o objeto parece necessário, e certas habilidades analíticas estariam mais em evidência. No segundo caso, ainda que um nível de análise possa/tenha que existir, as habilidades mobilizadas estariam mais ligadas à síntese e percepção das potencialidades e formas de construir sentido das diferentes linguagens. Ambas as habilidades são importantes.

O que pode parecer um gênero menor, na verdade, pode favorecer o domínio de modos de significação nas diferentes linguagens, o que a análise ou produção de uma foto convencional, por exemplo, pode não propiciar ${ }^{48}$. 


\begin{abstract}
O texto oficial tem o cuidado de indicar que o tema das comunicações e suas tecnologias é absolutamente novo no sistema escolar brasileiro, fato que justifica o volume de dados inseridos no tópico destinado a tratar os elementos relativos aos "novos" letramentos:

O espaço maior nesse trecho introdutório destinado aos novos letramentos e à cultura digital é devido tão somente ao fato de que sua articulação ao currículo é mais recente e ainda pouco usual, ao contrário da consideração dos "letramentos da letra" já consolidados ${ }^{49}$.

Nessa linha, o texto reforça o cuidado com a diversidade cultural:

É importante contemplar o cânone, o marginal, o culto, o popular, a cultura de massa, a cultura das mídias, a cultura digital, as culturas infantis e juvenis, de forma a garantir uma ampliação de repertório e uma interação e trato com o diferente. Ainda em relação à diversidade cultural, cabe dizer que se estima que mais de 250 línguas são faladas no país - indígenas, de imigração, de sinais, crioulas e afro-brasileiras, além do português e de suas variedades. Esse patrimônio cultural e linguístico é desconhecido por grande parte da população brasileira $^{50}$.
\end{abstract}

\title{
11. EIXOS DE COMPETÊNCIAS ALVEJADAS: SABER LER, PRODUZIR E FALAR!
}

Segundo a BNCC, para dar conta de suas tarefas, a Área de Linguagens do ensino básico opera de forma articulada a partir de quatro eixos de competências, a saber: "leitura", "produção", "oralidade" e "linguística" (tema tratado a partir da página 71 do texto oficial). É justamente no conjunto dos três primeiros eixos que encontramos pressupostos de um programa de educação midiática, nas perspectivas defendidas pelos mídia-educadores e educomunicadores. O quarto eixo volta-se para os temas formais da língua culta.

No caso das práticas relativas ao eixo da oralidade, o texto oficial inclui:

as práticas de linguagem como aula dialogada, webconferência, mensagem gravada, spot de campanha, jingle, seminário, debate, programa de rádio, entrevista, declamação de poemas, peça teatral, apresentação de cantigas e canções, playlist comentada de músicas, vlog de game, contação de histórias, diferentes tipos de podcasts e vídeos, dentre outras ${ }^{51}$.

Caberá ao aluno, basicamente:

49. Ibidem.

50. Ibidem, p. 66 .

51. Ibidem, p. 75.

52. Ibidem, p. 76.

Estabelecer relação entre fala e escrita, levando-se em conta o modo como as duas modalidades se articulam em diferentes gêneros e práticas de linguagem (como jornal de TV, programa de rádio, apresentação de seminário, mensagem instantânea etc.), as semelhanças e as diferenças entre modos de falar e de registrar o escrito e os aspectos sociodiscursivos, composicionais e linguísticos de cada modalidade sempre relacionados com os gêneros em questão ${ }^{52}$. 


\section{CAMPOS DE ATUAÇÃO}

Na BNCC, a partir da página 80, a organização das práticas de linguagem é discriminada por "campos de atuação", apontando para a importância da contextualização do conhecimento escolar.

São cinco os espaços de atuação a serem considerados pelos docentes no planejamento didático das atividades relacionadas ao aprendizado das diferentes linguagens: (1) o campo da vida cotidiana (somente anos iniciais); (2) o campo artístico-literário; (3) o campo das práticas de estudo e pesquisa; (4) o campo jornalístico/midiático; e finalmente (5) o campo de atuação na vida pública. Vale observar que os dois últimos aparecem fundidos nos anos iniciais do ensino fundamental, com a denominação "campo da vida pública".

\subsection{Jornalismo}

Mais uma vez, a Base Nacional Comum Curricular aproxima-se de uma realidade já vivida por milhares de crianças e jovens no Brasil a partir dos referenciais educomunicativos e mídia-educativos: a produção midiática com o gênero jornalístico. Foi o que ocorreu, por exemplo, a partir de 2008, em mais de seis mil escolas beneficiadas pelo Programa Mais Educação do MEC, envolvendo mais de dois milhões de alunos, quando da vigência do macrocampo "Comunicação e uso de mídias" (PROSPERO, 2013). O mesmo fenômeno é reportado com frequência pela Revistapontocom ${ }^{53}$, em relação ao trabalho mídia-educativo em escolas do Rio de Janeiro e de Recife.

\subsection{Vida pública}

No que diz respeito ao campo de atuação na vida pública, é ressaltado seu potencial para promover "a valorização dos direitos humanos e a formação de uma ética da responsabilidade" ${ }^{54}$, com a identificação e a valorização das manifestações dos movimentos sociais e populares, conforme reza a página 135 do documento:

No campo de atuação da vida pública ganham destaque os gêneros legais e normativos - abrindo-se espaço para aqueles que regulam a convivência em sociedade, como regimentos (da escola, da sala de aula) e estatutos e códigos (Estatuto da Criança e do Adolescente e Código de Defesa do Consumidor, Código Nacional de Trânsito etc.), até os de ordem mais geral, como a Constituição e a Declaração dos Direitos Humanos, sempre tomados a partir de seus contextos de produção, o que contextualiza e confere significado a seus preceitos.

Trata-se de promover uma consciência dos direitos, uma valorização dos direitos humanos e a formação de uma ética da responsabilidade (o outro tem direito a uma vida digna tanto quanto eu tenho).

Ainda nesse campo, estão presentes gêneros reivindicatórios e propositivos e habilidades ligadas a seu trato. A exploração de canais de participação, inclusive digitais, também é prevista. Aqui também a discussão e o debate de ideias e propostas assumem um lugar de destaque.
53. Para mais informações, cf. o site da revista disponível em: <http://planeta pontocom.org.br/produtos /revistapontocom/>. Acesso em: 18 abr. 2018.

54. Brasil, op. cit., 2017, p. 133. 


\author{
comunicação \& educação • Ano XXIII • número 1 • jan/jun 2018
}

55. Ibidem.

56. Sobre o conceito de "ecossistema comunicativo", cf. o artigo de Eliany Salvatierra Machado "Ecossistema cognitivo e comunicativo", disponível em: <http://www.usp.br/nce/ wcp/arq/textos/201.pdf>. Acesso em: 18 abr. 2018.

57. MÁRQUE; TALARICO, op. cit.

58. As secretarias de educação dos municípios podem contar com especialistas na área da educação midiática vinculados a universidades que possuem cursos de educação e comunicação.

O NCE-USP, núcleo que ressemantizou o conceito de educomunicação, continua oferecendo assessoria ao ensino formal.

Cf. mais informações no endereço: <http://nce-usp.blogspot.com.br/>. Acesso em: 12 maio 2018. O mesmo acontece com a ABPEducom (disponível em: <www. abpeducom.org.br $>$.

Acesso em: 12 maio 2018) e com o núcleo brasileiro da Alfamed (disponível em: $<$ https://redalfamed. org/contacto $>$. Acesso em: 12 maio 2018)
Assim, não se trata de promover o silenciamento de vozes dissonantes, mas antes de explicitá-las, de convocá-las para o debate, analisá-las, confrontá-las, de forma a propiciar uma autonomia de pensamento, pautada pela ética, como convém a Estados democráticos. Nesse sentido, também são propostas análises linguísticas e semióticas de textos vinculados a formas políticas não institucionalizadas, movimentos de várias naturezas, coletivos, produções artísticas, intervenções urbanas etc. ${ }^{55}$.

Por fim, o documento destaca a relevância dos diferentes campos de atuação da Área de Linguagens para o exercício da empatia e do diálogo.

No entanto, devemos estar atentos para o fato de que nenhuma dessas competências poderá ser adquirida pela simples dissertação a seu respeito por parte dos professores, no modelo de ensino bancário. Por sua natureza, a aquisição dessas habilidades exige vivências e práticas que serão adquiridas mediante procedimentos capazes de envolver e motivar os estudantes de forma construtivista, coletiva e solidária, em projetos de intervenção em seus respectivos ecossistemas comunicativos ${ }^{56}$.

A educomunicação se presta a esse serviço, dada sua origem na luta dos movimentos sociais pela conquista da liberdade de expressão, pela reafirmação do direito às diferenças e pelo reconhecimento dos direitos humanos, prioridade de todo o processo educativo ${ }^{57}$. Além do mais, a afirmação do protagonismo infanto-juvenil nos processos de aprendizagem sela o envolvimento das novas gerações com as metas pedagógicas, criando comprometimentos duradouros; enfim, educando.

\section{O QUE A MÍDIA-EDUCAÇÃO E A EDUCOMUNICAÇÃO TÊM A OFERECER}

Chegou o momento de uma conversa mais propositiva dos especialistas em educação midiática com os responsáveis pelas políticas públicas nos três níveis de governo (federal, estadual e municipal), a fim de mobilizar as autoridades para que sejam criados e implementados procedimentos que deem respostas às demandas que o próprio poder público já reconhece como de máxima urgência, conforme explicitado no próprio texto da BNCG.

No caso, evidencia-se o espaço para as duas categorias de pesquisadores e profissionais que trabalham justamente com a educação midiática e informacional, os mídia-educadores e os educomunicadores. A partir de nossa experiência, constatamos especificidades que se coadunam com a conformação de cada uma dessas especialidades. Para os mídia-educadores, por exemplo, a primazia é representada pelos elementos da BNCC que dizem respeito expressamente à presença das tecnologias da informação e dos meios de comunicação na sociedade e nas práticas educativas. Já no caso dos educomunicadores - para além da recepção crítica da mídia - interessa especialmente a própria gestão dos processos comunicativos, em propostas de autogestão no emprego das tecnologias a serviço da construção do aprendizado sobre práticas cidadãs ${ }^{58}$. 


\section{A TÍTULO DE CONCLUSÃO}

A proposta que mantemos e socializamos é levar à base curricular brasileira, no espaço de ação das secretarias municipais de educação, as ideias inovadoras de Anísio Teixeira e Paulo Freire, no sentido de construir projetos de educação que resgatem o protagonismo do professor e do aluno no chão do sistema educativo, pelo cumprimento dos dispositivos legais abertos a uma comunicação dialógica e participativa, como as identificadas e transcritas neste artigo. É o que denominamos "educomunicação possível".

Defendemos, nessa linha, a justeza da hipótese segundo a qual são criados pelas perspectivas que se abrem para as reformas curriculares novos tempos e novos espaços para uma práxis valorizadora do aluno e do professor no cotidiano da escola, enquanto sujeitos portadores do direito à fala. A edificação desse novo contexto dependerá, contudo, da vigilância e da ação articulada dos especialistas das áreas de mídia-educação e educomunicação.

\section{REFERÊNCIAS BIBLIOGRÁFICAS}

BATISTA, Augusto Gomes; LUGLI, Rosário; RIBEIRO, Vanda. Centralização e padronização dos currículos: posições e tomadas de posição. In: REUNIÃO NACIONAL DA ANPED, 37., 2015, Florianópolis. Anais... Florianópolis: UFSC, 2015. p. 1-23. Disponível em: <http://37reuniao.anped.org.br/wp-content/ uploads/2015/02/Sess\%C3\%A3o-Especial-05.pdf>. Acesso em: 17 abr. 2018.

BÉVORT, Evelyne; BELLONI, Maria Luiza. Mídia-educação: conceitos, história e perspectivas. Educação \& Sociedade, Campinas, v. 30, n. 109, p. 1.081-1.102, set./dez. 2009. Disponível em: <http://scielo.br/pdf/es/ v30n109/v30n109a08.pdf/>. Acesso em: 17 abr. 2018.

BRASIL. Ministério da Educação. Base Nacional Comum Curricular: educação é a base. 1. ver. Brasília, DF: MEC, 2016.

BRASIL. Base Nacional Comum Gurricular. 3. ver. Brasília, DF: Ministério da Educação, 2017. Disponível em: http://portal.mec.gov.br/index. php?option $=$ com_docman\&view $=$ download\&alias $=79601$-anexo-texto-bnccreexportado-pdf-2\&category_slug=dezembro-2017-pdf\&Itemid=30192. Acesso em: 12 maio 2018.

CARA, Daniel. \#BNCC: O que Paulo Freire e Anísio Teixeira diriam sobre a base curricular? UOL Educação, São Paulo, 20 dez. 2017. Disponível em: $<$ https:/ / danielcara.blogosfera.uol.com.br/2017/12/20/bncc-o-que-paulofreire-e-anisio-teixeira-diriam-sobre-a-base-curricular $/$ ?cmpid=copiaecola $>$. Acesso em: 10 jan. 2018.

LOPES, Marina; OLIVEIRA, Vinícius de. As oportunidades e os riscos com a chegada da Base Nacional. Porvir, São Paulo, 22 dez. 2017. Disponível em: <http:/ / porvir.org/as-oportunidades-e-os-riscos-com-a-chegada-da-basenacional/>. Acesso em: 12 maio 2018. 
MÁRQUES, Fernanda Telles; TALARICO, Blueth Sabrina Lobo Uchôa. Da comunicação popular à educomunicação: reflexões no campo da "educação como cultura”. Atos de Pesquisa em Educação, Blumenau, v. 11, n. 2, p. 422-443, ago./nov. 2016.

PRÓSPERO, Daniele. Educomunicação e políticas públicas: os desafios e as contribuições para o Programa Mais Educação. 2013. 368 f. Dissertação (Mestrado em Interfaces Sociais da Comunicação) - Escola de Comunicação e Artes, Universidade de São Paulo, 2013. Disponível em: <http://www. teses.usp.br/teses/disponiveis/27/27154/tde-30012014-105832/pt-br.php >. Acesso em: 17 abr. 2018.

SOARES, Ismar de Oliveira. Comunicação/educação: a emergência de um novo campo e o perfil de seus profissionais. Contato, Revista Brasileira de Comunicação, Arte e Educação, Brasília, DF, ano 1, n. 2, p. 19-74, 1999.

Educomunicação: as múltiplas tradições de um campo emergente de intervenção social na Europa, Estados Unidos e América Latina. In: LIMA, João Cláudio Garcia R.; MELLO, José Marques de (orgs.). Panorama da comunicação e das telecomunicações no Brasil - 2012/2013 - Memória. Brasília, DF: Ipea, 2013. p. 169-202. Disponível em: <http://www.ipea. gov.br/portal/images/stories/PDFs/livros/livros/livro_panorama_da_ comunicacao_v4.pdf>. Acesso em: 18 abr. 2018.

. A Educomunicação possível: uma análise da proposta curricular do MEC para o ensino básico. Comunicacão \& Educação, São Paulo, v. 21, n. 1, p. 13-25, maio 2016. Disponível em: <https:/ / www.revistas.usp.br/comueduc/ article/view/110451>. Acesso em: 12 maio 2018.

SOARES, Ismar de Oliveira; VIANA, Claudemir; XAVIER, Jurema Brasil (orgs.). Educomunicação e suas áreas de intervenção: novos paradigmas para o diálogo intercultural. São Paulo: ABPEducom, 2017. Disponível em: <https://issuu.com/abpeducom/docs/livro_educom_-_paginas_em_ sequencia $>$. Acesso em: 17 abr. 2018.

WILSON, Carolyn et al. Alfabetização midiática e informacional: currículo para formação de professores. Brasília, DF: Unesco; UFTM, 2013. Disponível em: <http://unesdoc.unesco.org/images/0022/002204/220418por.pdf>. Acesso em: 17 abr. 2018. 